
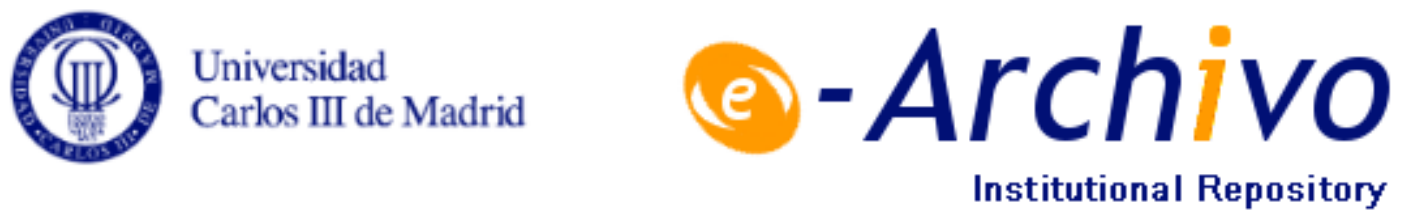

This is a postprint version of the following published document:

Basco, S. and Mestieri, M. (2017). Mergers Along the Global Supply Chain: Information Technologies and Routine Tasks. Oxford Bulletin of Economics and Statistics, pp. 1-28. Available in: https://doi.org/10.1111/obes.12165

(C) Wiley 


\title{
Mergers Along the Global Supply Chain: Information Technologies and Routine Tasks*
}

\author{
Sergi Basco $\dagger$ and Martí Mestieri
}

$\dagger$ Universidad Carlos III, Getafe, Spain (e-mail: sergi.basco@uc3m.es)

\$Northwestern University, Northwestern, Evanston, USA (e-mail: marti.mestieri@north

western.edu.)

\begin{abstract}
This paper empirically analyses how the adoption of Information Technologies (IT) has changed the organization of global supply chains. We focus on international mergers, which are a growing and important component of foreign direct investment. We use data on North-South mergers and acquisitions (M\&As). We show that the effect of IT adoption on the number of vertical M\&As is decreasing with the routine intensity of the industry. Our interpretation is that the IT revolution enabled new monitoring mechanisms. This allowed Northern headquarters to better monitor suppliers, especially those in less routine-intensive industries - which were harder to monitor before.
\end{abstract}

\section{Introduction}

The Information Technologies (IT) revolution has changed the organization of the firm. ${ }^{1}$ It has been argued that IT have allowed headquarters to better monitor suppliers, as the next quote from the New York Times (19 March 2011) illustrates.

“... supply lines are longer and far more complex than in the past. The ability to manage these complex networks, experts say, has become possible because of technology - Internet communications, RFID tags and sensors attached to valued parts, and sophisticated software for tracking and orchestrating the flow of goods worldwide."

This paper provides a first attempt to empirically study how the adoption of these IT has affected the international organization of the supply chain of Northern firms. We focus on Mergers and Acquisitions (M\&As), which are an important and growing fraction of

JEL Classification numbers: F23, F14, D23, L22

*A previous version of this paper was circulated under the title 'Deconstructing International Mergers: Information Technologies and Routineness'. We thank Daron Acemoglu, Pol aNTRàs, Paula Bustos, Nicholas Bloom, Alessandro Bonatti, Thomas Chaney, Rosario Crinò, Arnaud Costinot, Klaus Desmet, Gino Gancia, Francine Lafontaine, Mar Reguant, Steve Tadelis and seminar participants at MIT, TIGER Forum, Toulouse School of Economics and UC3M, the editor and two anonymous referees for useful comments and suggestions. Basco acknowledges financial support from the Spanish Ministry of Science and Innovation, grant MDM 2014-0431. Mestieri acknowledges financial support from the Agence Nationale de la Recherche. The remaining errors are our own.

${ }^{1}$ See, for example, Bloom et al. (2014) for an empirical analysis of the impact of ICT technologies on the organization of Northern firms. The fall in communication costs has also expanded the range of jobs that are being offshored. See, among others, Blinder (2006), Crinò (2010), Ebenstein et al. (2014) and Oldenski (2011). 
foreign direct investment (FDI). ${ }^{2}$ More broadly, the paper contributes to the analysis of the effect of IT on the organization of the firm, by exploiting international variation in IT adoption.

The starting premise of our paper is that contractual frictions play an important role in the organization of global supply chains. This is a well documented fact in the international trade literature. ${ }^{3}$ We focus on monitoring problems as the source of contractual frictions. In line with our emphasis on monitoring, the World Investment Report (UNCTAD, 2013) identifies communication and information flows, which allow better monitoring and coordination, as key elements for effective governance of global supply chains.

To investigate how the IT revolution has affected M\&As, we develop a task-based model of organizational choice of upstream production with agency problems. Tasks differ on how closely they follow tight and standardized procedures. Standardized tasks are easier to monitor. We assume that the IT revolution reduces the monitoring costs in an industry by expanding the set of tasks that can be easily monitored. This is consistent with the findings of Baker and Hubbard (2003) for the trucking industry, Bloom et al. (2013) for a survey of US manufacturing plants and the growing international trade literature highlighting the importance of IT in facilitating a finer 'slicing' of the global supply chain. Following the international trade literature, we consider that the level of IT infrastructure is a country characteristic and, thus, exogenous to firms' choice. ${ }^{4}$

The expansion in monitorable tasks generated by the IT revolution causes a relatively higher fall in monitoring costs of previously harder-to-monitor industries. This delivers the most salient prediction of our model: harder-to-monitor industries receive relatively more M\&As with the IT revolution. The testable implication of this complementarity result is that countries abundant in IT infrastructure receive relatively more M\&As in harder-to-monitor industries. ${ }^{5}$

To give empirical content to the notion of hard-to-monitor industries, we use the routine task index developed by Autor and Dorn (2009). An industry is defined as routine-intensive when the average task performed in that industry requires relatively tight and standardized procedures. Accordingly, we argue that it is more difficult to monitor production in industries with less standardized tasks.

We focus our empirical analysis on vertical North-South M\&As within the manufacturing sector. The reason is that, as emphasized, among others, in Antràs (2003) and Antràs, Desai and Foley (2009), agency problems are more severe when a supplier is located in the

\footnotetext{
${ }^{2}$ According to UNCTAD (2000), Table I.1, the ratio of the value of global cross-border M\&As to the value of global FDI is about $80 \%$. Moreover, the value of completed cross-border M\&As rose from less than $\$ 100$ billion in 1987 (which represented $72 \%$ of the total value of FDI inflows) to $\$ 720$ billion in 1999 (which represented $83 \%$ of the total value of FDI inflows).

${ }^{3}$ See Antràs (2014) for a survey of theoretical and empirical papers emphasizing the role of contractual frictions on the international organization of production.

${ }^{4}$ See, for example, Baldwin (2012), Basco and Mestieri (2013) and Antràs and Chor (2013).

${ }^{5}$ Our model considers two organizational forms: M\&A and 'O-organtization'. O-organizations embed the better alternative to mergers between arm's length contracting and greenfield investments. We choose this simple classification to emphasize that our focus and results (both theoretical and empirical) are on the effects of IT on mergers across industries. It would be interesting to study also the effects of IT on the choice across different organizational forms (e.g. greenfield vs. M\&As). Unfortunately, comparable comprehensive cross-country data of the type, we use for mergers are not available for other organizational modes.
} 
South, while they are much less important in the North. ${ }^{6}$ We obtain data on mergers from SDC Thomson Platinum, which is the most comprehensive data set publicly available. A merger is classified as vertical if (i) the 4-digit SIC codes of the target and acquirer firms are different and (ii) the output of the SIC code of the target firm is an input used to produce the output of the SIC code of the acquirer. We use the 1997 direct requirements U.S. Input-Output table to perform this exercise. ${ }^{7}$ Our variable of interest is the number of vertical M\&As by country and industry in the 1990s. We study the 1990s because the pattern of North-South trade dramatically changed in those years. As argued in Baldwin (2006), Blinder (2006) and Basco and Mestieri (2013), among others, the IT revolution was one of the main drivers of this change. ${ }^{8}$ Lastly, our proxy for adoption of IT at the country level is Internet users from WDI (World Bank), which is the most extensive Internet adoption variable available for Southern countries.

Consistent with the complementarity implied by our model, we show that the effect of the adoption of IT on the number of M\&As is decreasing with the routine intensity of the industry. Our interpretation is that, in Southern countries with low IT adoption, Northern headquarters only find optimal to acquire a firm in very routine-intensive industries, where monitoring problems are of little importance. However, in Southern countries with more IT adoption, Northern headquarters also find optimal to merge in less routine-intensive industries, because the adoption of IT reduces monitoring costs.

Quantitatively, we find that if IT adoption in a Southern country raises from the 25th to the 75th percentile of the distribution, ceteris paribus, the increase in the number of mergers in a low routine-intensive industry (e.g. non-metallic products) would be $29 \%$ higher than in a high routine-intensive industry (e.g. computer and electronics).

Given that our main result is on the interaction between IT infrastructure and the routine intensity of an industry, we include both country and industry fixed effects in our baseline regression. We also include country-industry varying controls for exports, intrafirm exports and capital inflows (FDI). The result also holds when we control for factor price differences to account for Heckscher-Ohlin determinants of trade (Romalis, 2004).

A concern with our measure of IT infrastructure is that it could be a proxy for the wealth or productivity of a country. To address this concern, we add the interaction between routine intensity and aggregate productivity and the interaction with gross domestic product. Our results are robust to the inclusion of these interactions. A similar concern is that our measure of IT adoption is a proxy for institutions. We show that our results are robust to include the interaction between routine intensity and property rights institutions and the interaction with contracting institutions. Finally, we also show that our results hold when we control for the interaction of IT infrastructure and skill intensity of the industry. ${ }^{9}$

\footnotetext{
${ }^{6}$ Following the reasoning of focusing on Southern countries, we could look as well at South-South M\&As. However, we have a very low number of observations in our data for South-South M\&As, which precludes their analysis. A country is defined as Southern if the GDP per capita (PPP adjusted) in 2000 is lower than the $50 \%$ of the United States. Romalis (2004) uses the same definition.

${ }^{7}$ This definition is similar to Alfaro and Charlton (2009), Atalay, Hortacsu and Syverson (2014) and Ramondo, Rappoport and Ruhl (2012).

${ }^{8}$ We emphasize the effect of the IT revolution on North-South trade. However, there exists evidence that Internet adoption increased exports also in the North. See, for example, Freund and Weinhold (2004).

${ }^{9}$ Our results are also robust to alternative measures of routine intensity and IT adoption. First, we use ERP adoption at industry level as a proxy for routine intensity. ERP software allows headquarters to better monitor production (Bloom
} 
Related literature. This paper is related to different strands of the literature. A vast literature on organizational economics followed the seminal work of Williamson (1975) on the nature of the firm. The make-or-buy decision has also been studied in the context of multinational firms. For example, Antràs (2003) and Antràs and Helpman $(2004,2008)$ use the incomplete contracts approach of Grossman and Hart (1986). In our model, the rents of the supplier come from a moral hazard problem in the production of tasks.

In the empirical section, we use the routine intensity index of Autor and Dorn (2009), which measures the tightness and standardization of the production process, as a proxy for how hard-to-monitor an industry is. The closest paper to our work is Costinot, Oldenski and Rauch (2011). They use the routine intensity of an industry as a proxy for contractibility and show that intrafirm trade tends to be higher in less routine-intensive industries. One difference is that they use the importance of problem solving as a measure of routine intensity. In addition, we are interested in the effect on mergers.

A small but growing literature has studied the relationship between mergers and trade. On the empirical side, for example, Breinlich (2008) studies the effects of NAFTA on mergers and shows that there is no robust link between tariff reductions and the number of cross-border M\&As. On the theoretical side, Neary (2007) shows that trade liberalizations can trigger international (horizontal) merger waves. More recently, Nocke and Yeaple $(2007,2008)$ analyse the choice between mergers and greenfield investment. However, they do not study how this choice is affected by the IT revolution. In our model, parent firms 'cherry pick' acquired firms to be the most productive within their industry. This behaviour has been documented in Arnold and Javorcik (2009) for Indonesia and Guadalupe, Kuzmina and Thomas (2012) for Spain. ${ }^{10}$

Another related paper is Head and Ries (2008). By developing a control-based model of FDI, they derive and test a gravity equation of FDI stocks. Although we also emphasize monitoring problems as a determinant of FDI activities, the goal of our paper is different. We study how the IT revolution affects the choice of Northern firm in engaging in M\&As activities and how this effect depends on the monitoring problems of the industry. Therefore, the contribution to this literature is to link the adoption of IT with the relative benefit of acquiring a firm. By showing how IT adoption affects the incentives of engaging in M\&As, this paper complements other studies that emphasize country characteristics in shaping the FDI mode (e.g. Javorcik, 2004).

Antràs, Garicano and Rossi-Hansberg (2006a, b) and Bloom et al. (2014) among others study, both theoretically and empirically, the effects of reductions in communication costs (IT revolution) on the internal organization of the firm. Bloom et al. (2013) suggest that firms that have improved their management practices through performance monitoring, targets and incentives have higher levels of investment in IT. Fort (2016) shows that communication technologies usage is a predictor of production fragmentation and offshoring.

et al., 2014). We find that the effect of IT adoption on the number of M\&As is larger in those industries with lower usage of ERP (i.e. more monitoring problems). Then, we use Internet penetration rates (Comin and Mestieri, 2010) as an alternative measure of IT adoption. We show that our result holds when using this alternative measure of IT adoption.

${ }^{10}$ Since our model is static, we abstract from subsequent improvements in acquired firms as documented in Arnold and Javorcik (2009) and Javorcik and Poelhekke (2016) among others. 
To the best of our knowledge, this is the first paper that studies how the IT revolution has changed the incentives to engage in M\&As.

The next section develops a model to guide the empirical section. Section III discusses our data. Section IV presents the main empirical results and section V shows the robustness checks. The concluding remarks are in section VI.

\section{Theoretical framework}

The goal of this section is to lay out a theoretical framework that guides our empirical exercise. We develop a stylized model of organizational choice of upstream production. The model provides a micro-foundation for monitoring costs and analyses how the number of mergers is affected by industry characteristics and IT adoption.

We consider a North-South economy. There is one Northern country and $c=1, \ldots, C$ Southern countries. There are $s=1, \ldots, S$ industries. A final good producer (or headquarters) wants to produce abroad a measure $N_{s} \geqslant 0$ of differentiated input varieties within each industry $s$. The final good producer combines input varieties into a final good. Input production can be located in any country, while final good production is located only in the North. ${ }^{11}$

We are interested in analysing the organizational choice of a final good producer. The final good producer can choose between two organizational modes $X \in\{M, O\}$. It can either acquire an existing intermediate supplier (M\&A) denoted by $M$-organization, or it can choose some other organizational form, denoted by $O$-organization. This alternative organizational mode subsumes the best alternative between greenfield investments and arm's length contracting. We choose this classification to emphasize that our focus and results are on mergers and acquisitions.

Production function. - Labour is the only factor of production. To produce an input, a worker has to perform $\mathcal{T}$ complementary tasks in a given firm. Production is carried out by assembling tasks in a Leontief fashion. Formally, a worker employed in firm $j$ produces $a(j) \min _{t \in \mathcal{T}} q(t)$, where $a(j)$ denotes the labour productivity of firm $j$ and $q(t)$ takes the value of 1 if task $t$ is performed successfully and 0 otherwise.

Agency problems. When an agent performs a task $t \in \mathcal{T}$, he can either exert high $(H)$ effort at a cost $e(c)$ or low $(L)$ effort at no cost. We allow the effort cost $e(c)$ to differ across countries, $c$, to capture differences in human capital, institutional arrangements, etc. Effort is not observable by the headquarters, while the output is observable.

Headquarters have access to a monitoring technology. This technology allows headquarters to detect when an agent exerts low effort with probability $\pi(c, X)$, which varies across countries, $c$, and organizational modes, $X$. Upon detection of shirking, a penalty proportional to the effort cost $\alpha e(c)$ can be imposed, $0 \leqslant \alpha \leqslant 1$.

The role of routine intensity. A central premise of the paper is that industries differ on how verifiable their production is. Both in this model and in our empirical exercise, we capture this idea by having heterogeneous tasks across industries. Tasks differ in how closely

\footnotetext{
${ }^{11}$ We abstract from transportation costs. Our results hold if there exists an iceberg transportation $\operatorname{cost} \tau$ for shipping to the North. To see that, re-scale the productivity measure $a$ to $a / \tau$, and all the stated results hold for the re-scaled productivity.
} 
they follow tight and standardized procedures. ${ }^{12}$ Tasks can either be 'standardized,' in the sense that they follow tight and standardized procedures, or discretional. The difference between standardized and discretional tasks is that it is easier to infer whether high effort was exerted in standardized tasks than in discretional tasks.

For simplicity, in the main text, we assume that effort can be perfectly inferred from observing output in standardized tasks, while this is not the case for discretional tasks. ${ }^{13}$ If an agent exerts high effort in a discretional task, the probability of output being usable for production is $P_{H}$. If the agent exerts low effort, the probability is $P_{L}\left(<P_{H}\right)$. We assume that agents and headquarters are risk neutral and normalize their outside option to zero. We assume that it is optimal for the headquarters to induce high effort in all tasks. ${ }^{14}$ Appendix B shows that the payment offered to induce a worker to exert high effort is $e(c)(1-\alpha \pi(c, X)) /\left(P_{H}-P_{L}\right)$. As workers are paid their outside option for standardized tasks, ${ }^{15}$ a worker in an industry with $\mathcal{D}$ discretional tasks is paid

$$
\mathcal{D} e(c) \frac{1-\alpha \pi(c, X)}{P_{H}-P_{L}} \text {. }
$$

Note that the payment to a worker (1) is increasing in the number of discretional tasks $\mathcal{D}$ and decreasing in the probability of detecting shirking, $\pi(c, X)$.

As we discussed, a central premise of the paper is that industries differ on how verifiable production is. To capture this idea, we denote by $\mathcal{D}=\mathcal{T}-s$ the number of discretional tasks performed in industry $s$. Motivated by the fact that the routine task index used in the empirical section measures how closely a task follows tight and standardized procedures, we label the industry index $s$ as the routine intensity of the industry. Thus, equation (1) means that payments to workers are decreasing in the routine intensity index $s$.

The expected cost of producing one unit of output in a firm with productivity $a(j)$ is

$$
\frac{R(s, c, X) w_{c}}{a(j)},
$$

where $R(s, c, X) \equiv \frac{\mathcal{T}_{-s}}{P_{H}^{\mathcal{T}-s}} \cdot \frac{1-\alpha \pi(c, X)}{P_{H}-P_{L}}$ and $w_{c} \equiv e(c)$. We can interpret $w_{c}$ as the marginal cost of effort and $R(s, c, X)$ as the mark-up paid by the headquarters to ensure high effort. ${ }^{16} \mathrm{In}$ other words, the final good producer has to pay rents to ensure the supply of inputs. Note that these rents are decreasing in the routine intensity index $s$.

Organizational choices. There is a technological difference between $M$ - and $O$ organizations. If the final good producer decides to acquire an input supplier, it inherits the productivity of the acquired supplier. For each industry and country, we assume that

\footnotetext{
${ }^{12}$ As it will become apparent in section III, this modelling choice is motivated to draw a connection with the routine task intensity index (RTI), which measures how closely a task follows tight and standardized procedures.

${ }^{13}$ In Appendix C of the working paper version Basco and Mestieri (2016), we relax the stark separation between standardized and discretional tasks. We allow for tasks to differ in their probability of being caught shirking in a continuous manner, $\pi(t, c, X)$, rather than having only two levels. We show that our results hold in this generalized set-up.

${ }^{14}$ Appendix B derives a sufficient condition for having high effort being always optimal. This boils down to the difference $P_{H}-P_{L}$ being larger than a threshold and the expected penalty not being arbitrarily large.

${ }^{15}$ Appendix $C$ in the working paper version, Basco and Mestieri (2016), departs from this zero-normalization and presents a model in which each task is paid a positive amount to derive the same results as in the main text.

${ }^{16}$ As long as $e(c)>P_{H}, R(s, c, X)>1$.
} 
there is a mass one of potential suppliers with productivity $a \sim F(a)$, with a continuously decreasing probability density function and support $a \in[a, \bar{a}], \bar{a} \leqslant \infty .{ }^{17}$ If headquarters engage in an $O$-organization, they can either use their in-house productivity, $a(s, O)$ or they can decide to inherit the productivity of the supplier. The former case can be interpreted as a greenfield investment. The latter can be thought of an arm's length relationship in which the productivity is inherited from the supplier contracted. ${ }^{18}$ Thus, the $O$-organization represents the best competing alternative to M\&As.

Organization and location choice. - The expected production cost per unit of output in industry $s$, country $c$ and input $j$ under organization $X$ is

$$
\kappa(s, c, X, j) \equiv \frac{R(s, c, X) w_{c}}{a_{s c j}(X)},
$$

where $w_{c}$ is the price of labour in country $c$ and $a_{s c j}(X)$ is the productivity of the supplier of the $j$ th input. The final good producer wants to minimize the production costs for each intermediate input used in production. Note that the choice of the set of locations and organizational modes is independent of the amount demanded of each particular intermediate. Hence, the location-organization choice problem can be solved independently from the demand levels of each intermediate. Thus, we do not need to specify the demand for each particular intermediate in each industry. The final good producer chooses the country of origin and the organizational form for each intermediate according to

$$
\begin{aligned}
\min _{\{m(s, c, O), a(s, c, M)\}} & \int_{0}^{1} \mathrm{~d} s \int_{0}^{N_{s}} \mathrm{~d} j \sum_{c, X} \kappa(s, c, X, j) \quad \text { s.t. } \\
N_{s} & =\sum_{c=1}^{C}\{m(s, c, O)+1-F(a(s, c, M))\}, \\
m(s, c, O) & \geqslant 0, \quad a(s, c, M) \geqslant 0 \quad \forall s \in S, c \in C,
\end{aligned}
$$

where $\kappa(s, c, X, j)$ is defined in (3), $j$ indexes intermediates used in production and $m(s, c, O)$ is the mass of intermediates in industry $s$ and country $c$ produced with an $O$-organization. Finally, $a(s, c, M)$ denotes the productivity threshold of firms with an $M$-organization in country $c$ and industry $s$, so that $1-F(a(s, c, M))$ is the mass of intermediates produced in country $c$ and industry $s$ under an $M$-organization. Therefore, the Northern firm chooses for each country and industry, the mass of intermediates produced with an $O$-organization, $m(s, c, O)$, and the productivity threshold of firms with an $M$-organization, $a(s, c, M)$.

Two comments on the location-organizational choice problem (4). First, to characterize the solution, it suffices to specify two objects for each country $c$ and industry $s$ : (i) the productivity threshold above which firms are acquired and (ii) the mass of intermediates produced under an $O$-organization. These two thresholds pin down the total number of intermediates in industry $s$ produced in country $c, m(s, c, O)+1-F(a(s, c, M))$. Note also that thresholds enter directly the objective function because they determine the range

\footnotetext{
${ }^{17}$ This nests, amongst others, the Pareto and exponential distributions. Pareto distributions provide a good description of productivity distributions (e.g. Eaton, Kortum and Kramarz, 2011, for France).

${ }^{18}$ In the case that productivity is inherited from the contracted supplier, the pool of potential suppliers coincides with the pool of targets for a merger.
} 
of intermediates produced in country $c$ and industry $s .{ }^{19}$ The second remark is that the organizational choice problem (4) consists of $s$ separate problems, one for each industry. So, the problem could be specified separately for each industry $s$ (and the outer integral in $s$ be dropped).

The solution to this problem is given by a threshold cost $\bar{\kappa}(s)$ for each industry, such that all intermediates in industry $s$ are produced at a lower or equal cost. For example, suppose that in industry $s$ there are $O$-organizations in country 1 , and mergers in countries 1 and 2 , then

$$
\bar{\kappa}(s)=\frac{R(s, 1, O) w_{1}}{a(s, O)}=\frac{R(s, 1, M) w_{1}}{a(s, 1, M)}=\frac{R(s, 2, M) w_{2}}{a(s, 2, M)} .
$$

Before turning to the study of the IT revolution and its testable implications, note that with the structure we have imposed on the role of routine intensity, we have already one testable prediction. (All proofs are in Appendix B).

Proposition 1. Ceteris paribus, in each Southern country, the number of M\&As is increasing in the routine intensity of the industry.

This result is intuitive. It states that industries with higher routine indexes (low monitoring costs) should have more mergers than industries with low routine indexes. This result is a direct consequence from the assumption that more routine-intensive industries have to incur lower monitoring costs because they have a lower share of discretional tasks. Thus, it cannot be that in a given Southern country there are more mergers in a low routine-intensive industry than in a high routine-intensive industry.

\section{The IT revolution and testable implications}

We frame the IT revolution as an improvement in the capabilities of the final good producer to monitor the production process of the supplier. For example, headquarters may acquire more easily relevant information on the production process in real time. Thus, our assumption is that the IT revolution reduces monitoring costs.

Assumption 1. Let $i_{c}$ denote the level of IT adoption in country $c$. The probability of detecting shirking in country $c$ and organizational choice $\mathrm{X}, \pi\left(c, X ; i_{c}\right)$, is increasing in $i_{c}$. That is, the monitoring technology becomes more efficient as IT diffuses in country $c$.

Improvements in the monitoring technology translate into reductions in the rents paid to suppliers. Formally, from equation (2) we see that rents paid under any organizational

${ }^{19}$ The exact expressions are

$$
\begin{aligned}
& \int_{0}^{N_{s}} \kappa(s, c, O, j) \mathbf{1}_{j \in\{s, c, O\}} \mathrm{d} j=\hat{m}(s, c, O) \frac{R(s, c, O) w_{c}}{a_{s}(O)}+\int_{a(s, c, O)}^{\infty} \frac{R(s, c, O) w_{c}}{a} f(a) \mathrm{d} a, \\
& \int_{0}^{N_{s}} \kappa(s, c, M, j) \mathbf{1}_{j \in\{s, c, M\}} \mathrm{d} j=\int_{a(s, c, M)}^{\infty} \frac{R(s, c, M) w_{c}}{a} f(a) \mathrm{d} a,
\end{aligned}
$$

where the indicator function $\mathbf{1}_{j \in\{s, c, X\}}$ denotes whether the $j$ th intermediate is produced under $\{s, c, X\}, \hat{m}(\cdot)$ denotes the mass of firms set-up with in-house technology, $a_{s}(O)$ and $a(s, c, O)$ denotes the productivity level of the least productive firm that has received an arm's length contract. 
form $R(s, c, X ; i)$ weakly decrease with $i .^{20}$ Note that in our exercise we take the level of IT as a country characteristic and, thus, exogenous to firms' choice. This assumption has the following testable implication.

Proposition 2. Ceteris paribus, as IT adoption increases in country $c$, new mergers occur in harder-to-monitor industries.

This result relates to the extensive margin of the organizational choice. It states that as a country increases its level of IT adoption, if new industries start having mergers, these industries have higher monitoring costs (and lower routine intensity indexes) than the old industries which already experienced mergers.

Finally, our micro-foundation for the rents paid $R(s, c, X ; i)$ delivers our main result. There is a negative complementarity between the routine intensity index $s$ and the IT adoption index $i$. That is, industries that are harder-to-monitor (i.e. with a lower routine intensity index) experiment relatively larger gains from IT adoption. The intuition is that, in harder-to-monitor industries, there are more tasks that need to be monitored. Hence, an improvement in the monitoring technology is more beneficial in these industries. Formally, this is captured in the negative 'cross partial' between $s$ and $i$ in (2).

While our theoretical framework presents, in our view, a compelling reason for this complementarity to exist, this is ultimately an empirical question. The following result presents the main testable prediction of our model.

Proposition 3. Ceteris paribus, Southern countries with better IT infrastructure (higher i) receive relatively more $M \& A s$ in harder-to-monitor (less routine-intensive) industries.

This result embeds the complementarity between the routine intensity of an industry and the IT revolution. Proposition 3 informs us on how the relative number of mergers varies across industries and countries with the IT revolution. The result states that the increase in the number of mergers is relatively higher in industries with more monitoring problems (i.e. those with a lower routine intensity index). The intuition comes from the complementarity between monitoring tasks and the IT revolution: industries with more monitoring problems benefit relatively more from the IT revolution. Finally, note that this result is independent of any other organizational form, as it compares the relative number of M\&As across industries and countries.

\section{Data description}

In order to test the empirical predictions of the model we need data on (i) North-South vertical M\&As, (ii) routine intensity measures at the industry level and (iii) IT adoption.

We obtain data on mergers and acquisitions from SDC Thomson Platinum. This the most comprehensive data set on mergers and acquisitions publicly available. For each merger, we know the country and 4-digit SIC codes of both the acquirer and the target, the share

\footnotetext{
${ }^{20}$ In what follows, we abuse notation and denote $i_{c}$ by $i$ when there is no risk of confusion.
} 


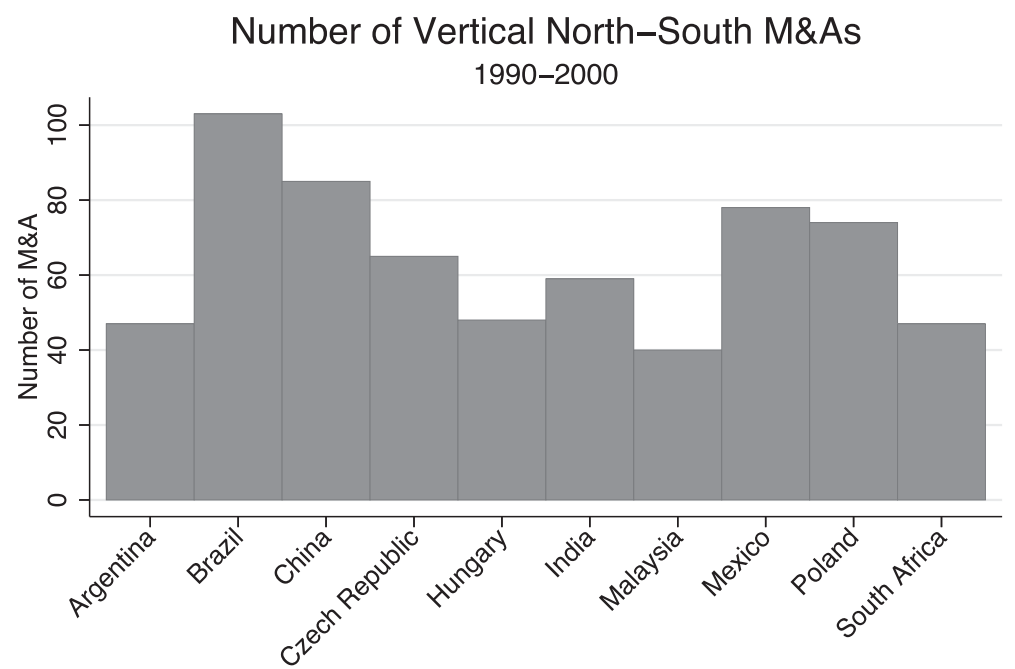

Figure 1 Top-ten Southern recipients of vertical mergers and acquisitions

owned after the acquisition and a description of the primary business of each firm. ${ }^{21}$ In our sample we have 3929 North-South M\&As between 1990 and 2000.

We define a merger as vertical if (i) the 4-digit SIC codes of the acquirer and the target firm are different and (ii) the output of the SIC code of the target firm is an input used to produce the output of the SIC code of the acquirer firm. We use the 1997 direct requirements U.S. Input-Output table to perform this exercise. This definition is similar to the procedure used in Alfaro and Charlton (2009) and Ramondo et al. (2012). ${ }^{22}$ We find that around a third of all North-South M\&As (1290) are vertical. Figure 1 represents the main recipients. Brazil and China are the two countries which received the highest number of vertical mergers from the North. Figure 2 shows the distribution of the number of M\&As by country and industry, which has an average of 5.5. Table 1 reports additional summary statistics.

To build a measure of routine intensity at the industry level, we use the routine task intensity index constructed by Autor and Dorn (2009). The RTI index proposed by Autor and Dorn (2009) is the ratio between the routine and the manual score of the occupation. ${ }^{23}$ Their interpretation is that workers in RTI-intensive occupations are required to follow tighter and more standardized procedures. Table 2 reports the most and least routine-intensive

\footnotetext{
${ }^{21}$ We only consider mergers in which the share owned after M\&As is larger than $50 \%$. This restriction eliminates very few mergers. Our empirical results do not hinge on excluding these observations. Other data are available. For example, the value of transaction, target stock price and book value. We disregard these data because it is only available for a tiny fraction of our observations.

${ }^{22}$ These papers find that input-output linkages are a good predictor of FDI. Note that the finding in Ramondo et al. (2012) of input-output linkages not being good predictors of intrafirm trade presumes that each stage of production should be integrated. If some intermediate stages of production are not integrated or exporting is done through intermediaries, part of unaffiliated sales should be imputed to the parent firm.

${ }^{23}$ The scores come from the dictionary of occupational titles. See Autor and Dorn (2009) for more details.
} 


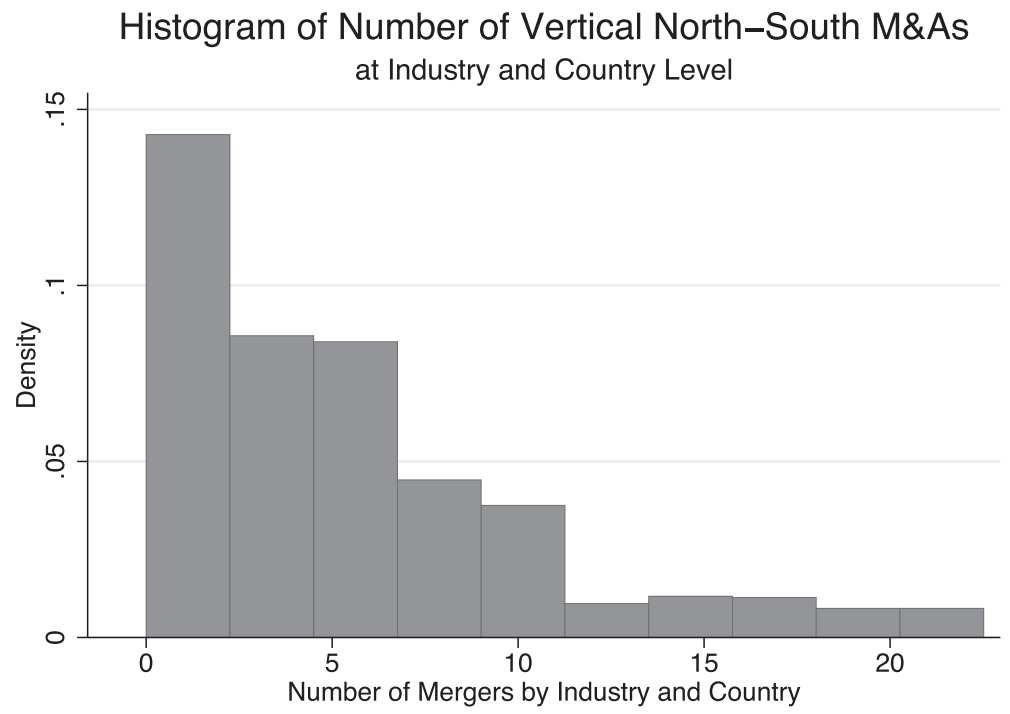

Figure 2 Distribution of North-South vertical M\&As at the country-industry level

TABLE 1

Summary statistics of North-South vertical mergers, 1990-2000

\begin{tabular}{llll}
\hline & \multicolumn{2}{l}{ Number of North-South vertical mergers, } & 1990-2000 \\
\cline { 2 - 4 } & By Country & By Industry & By Country-Industry \\
\hline Mean & 15.7 & 44.7 & 2.5 \\
St. Dev. & 24.4 & 43.2 & 3.0 \\
Maximum & Brazil, 103 & Chemicals, 169 & Brazil-Chemicals, 23 \\
p75 & Slovakia, 16 & Nonmetal. Manuf, 59 & Malaysia-Nonmetal. Manuf., * 3 \\
p25 & Perú,* 1 & Beverage \& Tobacco, 11 & Colombia-Textile,*1 1 \\
Minimum & Zimbabwe, * 1 & Leather \& Allied Prod., 1 & Greece-Transport Equip., 0 \\
Obs. & 60 & 21 & 381 \\
\hline
\end{tabular}

Note: *Denotes that there are other observations with the same number of M\&As.

occupations. Occupations related with transportation are the least routine-intensive and secretaries and bank tellers are the most routine-intensive. ${ }^{24}$

We aggregate these occupations at industry-level (3-digit NAICS) using 1990 U.S. Census data. ${ }^{25}$ Table 3 ranks the 21 manufacturing industries by routine intensity. The industries with less routine tasks are apparel and wood products and the industries with more routine tasks are machinery and fabricated metal products. Table 4 reports the industries that received the highest number of mergers in 1990 and 2000. From this table we can see that the top industries in the 2 years are similar. However, the average routine intensity of the top industries was higher in 2000.

\footnotetext{
${ }^{24}$ Note that many of these occupations relate to non-tradable activities. However, workers in these occupations work in industries that are exporting their produced goods and should be included when computing the routine intensity of the industry.

${ }^{25}$ We obtain very similar measure when we use 1980 U.S. Census data.
} 
TABLE 2

Highest and lowest routine-intensive occupations

\begin{tabular}{|c|c|c|c|c|c|}
\hline \multicolumn{3}{|c|}{ Lowest RTI } & \multicolumn{3}{|c|}{ Highest RTI } \\
\hline$R T I$ & Number & Description & RTI & Number & Description \\
\hline-1.39 & 813 & Parking lot attendants & 6.34 & 313 & Secretaries and stenographers \\
\hline-1.38 & 417 & Firefighting, prevention and inspection & 6.32 & 383 & Bank tellers \\
\hline-1.35 & 808 & Bus drivers & 6.28 & 96 & Pharmacists \\
\hline-1.25 & 809 & Taxi cab drivers and chauffeurs & 6.27 & 338 & Payroll and timekeeping clerks \\
\hline-1.20 & 463 & Public transportation attendants & 6.22 & 773 & Motion pictures projectionists \\
\hline
\end{tabular}

Note: Sample occupations that are aggregated to construct the industry routine intensity index.

Source: Autor and Dorn (2009).

TABLE 3

\begin{tabular}{lll}
\multicolumn{3}{c}{ Data on routine-intensive intensity by industry } \\
\hline$R T I$ & NAICS & Description \\
\hline 1.51 & 315 & Apparel \\
1.52 & 321 & Wood products \\
1.64 & 314 & Textile product mills \\
1.74 & 312 & Beverage and tobacco products \\
1.78 & 313 & Textile mills \\
1.80 & 316 & Leather and allied products \\
1.84 & 322 & Paper \\
1.85 & 327 & Non-metallic mineral products \\
1.86 & 337 & Furniture and related products \\
1.90 & 331 & Primary metals \\
1.93 & 324 & Petroleum and coal products \\
2.04 & 326 & Plastics and rubber products \\
2.13 & 336 & Transportation equipment \\
2.17 & 335 & Electrical equipment \\
2.22 & 311 & Food \\
2.23 & 334 & Computer and electronic products \\
2.24 & 339 & Miscellaneous \\
2.25 & 325 & Chemicals \\
2.32 & 323 & Printing and related support activities \\
2.33 & 332 & Fabricated metal products \\
2.40 & 333 & Machinery \\
\hline
\end{tabular}

Note: Source: Routine intensity index at industry-level calculated from the Autor and Dorn (2009)'s RTI values at occupation level.

We are not the first to use a routine index. In the international trade literature, Blinder (2006), Grossman and Rossi-Hansberg (2006) and Basco and Mestieri (2013), among others, argue that routine intensity is a common characteristic of jobs that have become offshorable after the IT revolution. We use our routine index as a proxy for monitoring problems. The assumption is that the more routine a task is, the more standardized the production process is and, thus, the less monitoring is needed. Ideally, we would like to have this routine measure for all countries. Since we do not have this information, we make 
the plausible assumption that the ranking of routine intensity in the United States is the same in all the countries in the sample.

As an alternative measure of monitoring problems at the industry level, we use adoption of Enterprise Resource Planning (ERP) systems. ERP systems allow managers to better monitor their supply chain by having access to relevant information of the production process, including production, inventory and finance. Thus, we assume that industries with higher adoption of ERP systems have less monitoring problems. We construct our measure of ERP adoption at industry level from the firm level data of Bloom et al. (2014), who give a score between 0 and 1 to each firm as a function of their level of ERP adoption. ${ }^{26}$ The industries with the highest ERP adoption are petroleum and coal products $(0.56)$ and chemicals $(0.54)$. The industries with the lowest ERP adoption are apparel $(0.23)$ and textile product miles $(0.25)$. The mean ERP adoption is 0.43 and the standard deviation is 0.09 . The correlation between ERP adoption and routine intensity is 0.57 . This suggests that ERP adoption has happened in routine-intensive industries, where tasks tend to be more codifiable and, presumably, easier to monitor by computer software.

Our baseline IT adoption measure is Internet users per hundred people from the WDI (World Bank). This measure has the advantage that it is the most extensive Internet adoption variable. We think of this measure as being a proxy for the IT infrastructure in place. To maximize the number of observations, our preferred measure is Internet users in 2000. In our sample, the mean number of Internet users (per 100 people) is 3.92 and the standard deviation is 6.73. The values of this variable for the top-5 host countries are Brazil (2.87), India (0.54), China (1.78), Mexico (5.16) and Poland (7.28). As a reference, this number is 43.1 in the US. We show in Appendix A that we obtain the same qualitative results using earlier dates (even though the number of countries for which we have data decreases substantially). Internet users goes from virtually zero for all countries in year 1990 to year 2000. However, there are missing observations for many countries prior to 1995.

Finally, as an alternative measure of IT adoption, we use Internet penetration rates from Comin and Mestieri (2010). The penetration rate is a measure of the diffusion curve of Internet in a given country relative to the US. This measure essentially captures the number of adopters after controlling for country size and income per capita using a structural model of technology adoption. If a country has the same penetration rate as the US, this measure would be one, while if it were less than the US, it would be between zero and one. The lowest penetration rate in our sample is Guinea, with 3\% of the US, while the US is the highest adopter. The average penetration rate in our sample is $29 \%$ and the standard deviation is $11 \%$. One drawback of this measure is that we only have data for around $40 \%$ of the countries in our sample.

\section{Empirical analysis}

In this section, we test the main result of the paper, Proposition 3. Section V performs additional robustness checks. ${ }^{27}$

\footnotetext{
${ }^{26}$ To do the crosswalk from SIC to NAICS we use employment weights according to the U.S. Census Bureau when the matching is not one-to-one.

${ }^{27}$ The working paper version (Basco and Mestieri, 2016, available from the authors' web pages) contains additional empirical tests. We show that, in line with Proposition 1, M\&As are increasing in the routine intensity of the industry
} 
TABLE 4

Top-5 North-South vertical M\&As

\begin{tabular}{cllllll}
\hline \multicolumn{2}{l}{ Year: 1990} & & & Year: 2000 & \\
\cline { 1 - 2 } \cline { 5 - 6 } RTI & NAICS & Defintion & & RTI & NAICS & Definition \\
\hline 1.85 & 327 & Non-metallic minerals & & 2.25 & 325 & Chemicals \\
1.52 & 321 & Wood products & & 1.90 & 331 & Primary metals \\
2.23 & 334 & Computer and electronics & 2.23 & 334 & Computer and electronics \\
1.93 & 324 & Petroleum and coal & 2.22 & 311 & Food \\
2.22 & 311 & Food & 2.04 & 326 & Plastics and rubber \\
\hline
\end{tabular}

Proposition 3 states that the effect of the IT revolution on the number of M\&As is higher in industries with high monitoring costs (low routine intensity). We test this result by investigating the sign of the interaction between Internet adoption and the routine intensity of the industry in the following regression:

$$
\mathbb{E}\left(M \& A_{s c}\right)=\exp \left(\beta \cdot I T_{c} \cdot R T I_{s}+\theta \cdot X_{s c}+\gamma \cdot X_{s} \cdot X_{c}+\delta_{s}+\delta_{c}\right),
$$

where $M \& A_{s c}$ is the number of vertical M\&As from the North to Southern country $c$ in industry $s$ between 1990 and 2000, $I T_{c}$ is IT adoption in country $c, R T I_{s}$ is routine intensity of industry $s, X_{s}, X_{c}, X_{s c}$ are industry, country and industry-country varying control variables and $\delta_{s}$ and $\delta_{c}$ are industry and country fixed effects. Proposition 3 implies that $\beta<0$. We have data for the 213 -digit NAICS industries and 60 Southern countries. ${ }^{28}$ We pool the data by country and industry. We do not exploit the time variation because we lack enough observations to do a regression analysis at the country-industry-year level.

Table 5 reports the coefficients of running equation (6) using a negative binomial regression. ${ }^{29}$ Column (1) reports our baseline regression. The coefficient is negative and statistically significant. ${ }^{30}$ It means that the effect of IT adoption on the number of mergers a country receives is decreasing with the routine intensity of the industry. A country with better IT receives relatively more mergers in low routine-intensive industries.

within each country. We also show that, in line with Proposition 2 , the routine intensity of new industries experiencing mergers within a country declines with the diffusion of IT (Table 4).

${ }^{28}$ The list of Southern countries receiving, at least, one vertical merger and acquisition from the North in our dataset is: Algeria, Argentina, Brazil, Bulgaria,Cambodia, Chile, China, Colombia, Congo, Costa Rica, Croatia, Czech Republic, Dominican Republic, Ecuador, Egypt, Estonia, Gabon, Ghana, Greece, Haiti, Hungary, India, Indonesia, Jamaica, Jordan, Kazakhstan, Latvia, Lithuania, Malaysia, Mexico, Morocco, Mozambique, Netherlands Antilles, Niger, Nigeria, Pakistan, Panama, Papua New Guinea, Peru, Philippines, Poland, Puerto Rico, Romania, Russia, Saudi Arabia, Slovakia, South Africa, Sri Lanka, Taiwan, Tanzania, Thailand, Tunisia, Turkey, Ukraine, Uruguay, Uzbekistan, Venezuela, Vietnam, Zambia and Zimbabwe.

${ }^{29}$ We prefer a Negative Binomial regression to a Poisson regression as our baseline specification in all of our count regressions. The reason is that a Negative Binomial regression does not impose that the mean and the variance of the process coincide - which we would be imposing by fitting a Poisson. Indeed, the Poisson regression is subsumed as a particular case of the Negative Binomial regression. We note that if we estimate Poisson regressions as our baseline specification, we obtain similar and significant coefficients as well. The Poisson regression has the advantage that it avoids the 'incidental parameters problem' when using fixed effects and yields consistent estimators. This is not guaranteed with the negative binomial regression. However, we follow the procedure described in Allison and Waterman (2002) of estimating an unconditional negative binomial regression with dummy variables, which they find to not generate the 'incidental parameters problem' in their simulations. Finally, we have also verified that our results hold when running linear regressions with fixed effects instead of count regressions.

${ }^{30}$ The standard errors are clustered by country. Our results remain if we cluster by industry (see Basco and Mestieri, 2016). 


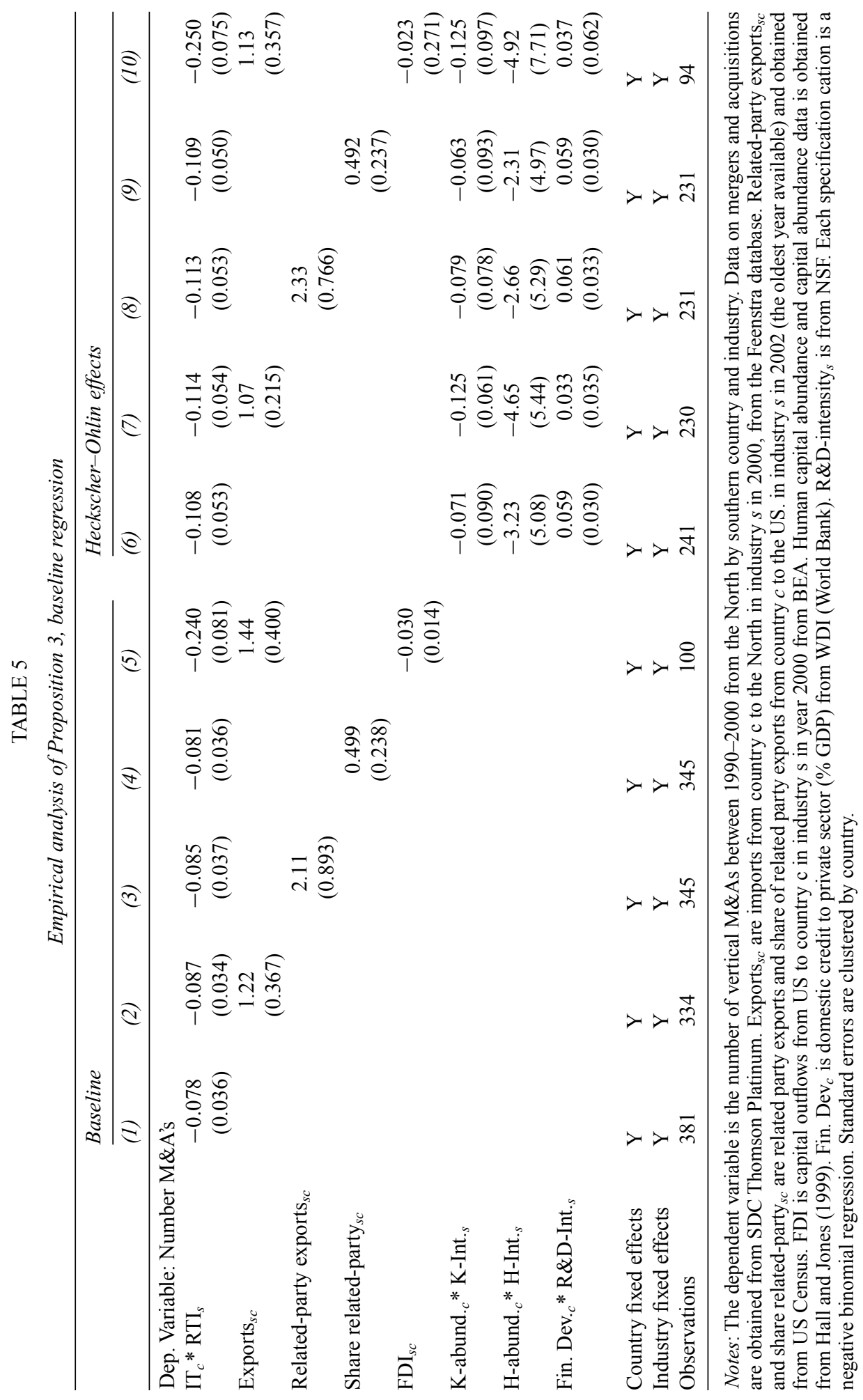


The coefficient is also quantitatively important. If Internet users in a country raise from the 25 th to the 75 th percentile of the Internet distribution, the increase in the number of mergers in the industry belonging to the 25th percentile of the RTI distribution (nonmetallic products) would be $29 \%$ higher than the industry in the 75 th percentile (computer and electronics). ${ }^{31}$

Standard trade theory predicts that countries export goods that intensively use the factor in which the country is relatively abundant. Therefore, to the extent that part of this trade is done through affiliates that have been acquired, we should control for these HeckscherOhlin effects. Column (6) includes the capital and human capital interactions of Romalis (2004). These are interactions between country's factor endowments and industry factor requirements. We also include a domestic credit interaction (interaction between financial development and R\&D-intensity of the industry). We include this interaction because the trade literature has also emphasized the importance of financial development as a source of comparative advantage. ${ }^{32}$ Note that the coefficient of interest remains negative and significant. The rest of the variables are not statistically significant.

A first concern is that we do not control for openness to trade of the country. That is, if a country does not export in a given industry (maybe because there is no production or trade costs are very high) is not very likely that a Northern country would acquire a company. Columns (2) and (7) include exports of each Southern country to the North at industry level, with and without Heckscher-Ohlin effects, respectively. Note that the coefficient of interest remains negative and significant. Moreover, as anticipated, the coefficient on exports is positive and significant. Industries that export to the North are more likely to receive vertical mergers.

Similarly, the existence of intrafirm trade in an industry may affect the choice of Northern headquarters. Columns (3) and (8) repeat the same regressions with related-party exports to the United States instead of total exports. We would like to have related-party exports to the world disaggregated at the industry level, but we do not have access to these data. The assumption is that the ranking of industries with more intrafirm trade in each Southern country would be the same as in the US. Note that the coefficient of interest remains negative in both columns. The coefficient on both related-party exports is positive. Finally, columns (4) and (9) includes the share of related-party exports to the United States (over total exports to the United States) by industry as control variable. The coefficient of interest remains negative and significant. The coefficient of the share of related-party exports is positive in both columns. It implies that countries are more likely to receive vertical mergers in industries with more intrafirm trade.

A related concern is that we should also consider capital inflows, in addition to exports. Unfortunately, the available disaggregated data are scarce. Columns (5) and (10) include

\footnotetext{
${ }^{31}$ Note that the prediction of our model is on the number of M\&As and not directly on intrafirm trade. Recently, Ramondo et al. (2012) have documented that less than 30 percent of affiliate sales are shipped within the firm for US multinationals. Our theoretical framework focuses on the organizational form and abstracts from the volume of intrafirm trade. Thus, our theoretical framework is silent on this dimension (as is our empirical setup, because we do not have the necessary data to explore this question).

${ }^{32}$ See, for example, Antràs and Caballero (2009), Basco (2012), Carluccio and Fally (2012), Kletzer and Bardhan (1987) and Manova (2013). Basco (2012) considers the same interaction. All control variables are for year 2000, except for the ones obtained from Hall and Jones (1999), which are for 1988. The assumption is that the ranking (either across countries or industries) remains stable during the sample period.
} 
capital outflows from United States to each Southern country and industry. Notice that the number of observations falls considerably. Thus, these results should be taken with a grain of salt. Nonetheless, the coefficient of interest remains negative and significant. The coefficient of exports also remains positive. The coefficient on capital inflows is negative in column (5) and not significant when we add the Heckscher-Ohlin terms (column 10).

This section has shown that the effect of IT Adoption on the number of vertical mergers is decreasing with the routine intensity of the industry. We have used the interaction between IT adoption and the RTI index to test this prediction. Table A1 in Appendix A shows that the results are robust to consider a dummy variable, High $\mathrm{RTI}_{s}$, equal to one if the RTI of industry $s$ is above the median (or mean), instead of the routine intensity index.

\section{Robustness checks}

This section performs several alternative robustness checks on the main empirical prediction.

Alternative measure of monitoring problems. Our interpretation of the results is that IT adoption has allowed headquarters to better monitor suppliers. We use routine intensity as a proxy of monitoring problems because it is, arguably, an exogenous characteristic of the tasks required in an industry. However, one could argue that routine intensity may proxy for other industry characteristics. In order to address this concern, we use the adoption of ERP systems from Bloom et al. (2014) as an alternative measure of monitoring problems. As discussed in section III, monitoring is more efficient in industries with a higher usage of ERP systems. Columns (1) to (10) in Table 6 repeat all our baseline regressions using ERP adoption. In all specifications, the interaction between adoption of ERP and IT is negative and significant.

Alternative measure of IT adoption. Next, we conduct robustness analysis on our measure of IT adoption. A possible concern is that Internet users is not a good proxy for IT adoption. To address this concern, we take the penetration rates estimated in Comin and Mestieri (2010) as an alternative proxy for IT adoption (see description in section III). Table 7 reports all baseline regressions using the penetration rate as a measure of IT adoption. The interaction between IT adoption and routine intensity remains negative and significant in all specifications.

Output. One concern is that monitoring may be easier in richer Southern countries (as suggested in, for example, Head and Ries, 2008) and, thus, they tend to have mergers in less routine-intensive industries. To address this concern, column (1) of Table 8 adds the interaction of production and routine intensity to our baseline regression. Note that the interaction between IT adoption and routine intensity remains negative and significant. However, the interaction with production is not significant.

Productivity. Similarly, it could be argued that more technologically advanced countries tend to receive mergers in industries with some other characteristics that are correlated with our measure of monitoring costs. We use total factor productivity (TFP) as an indirect measure of the technological level of a country. Column (2) of Table 8 includes the interaction between technology and routine intensity. The coefficient of interest remains negative and significant. Nonetheless, the interaction with TFP is not significant. 


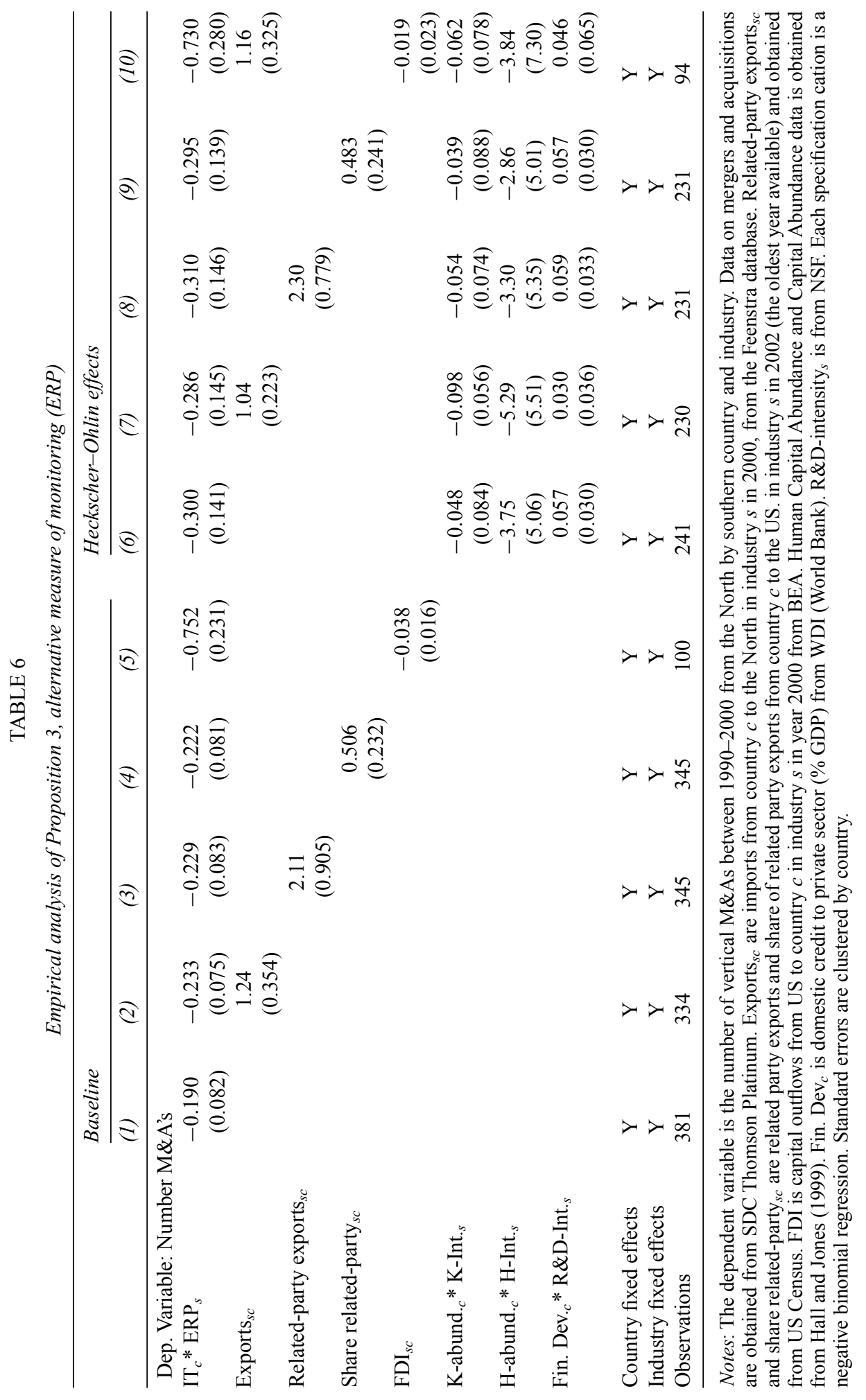




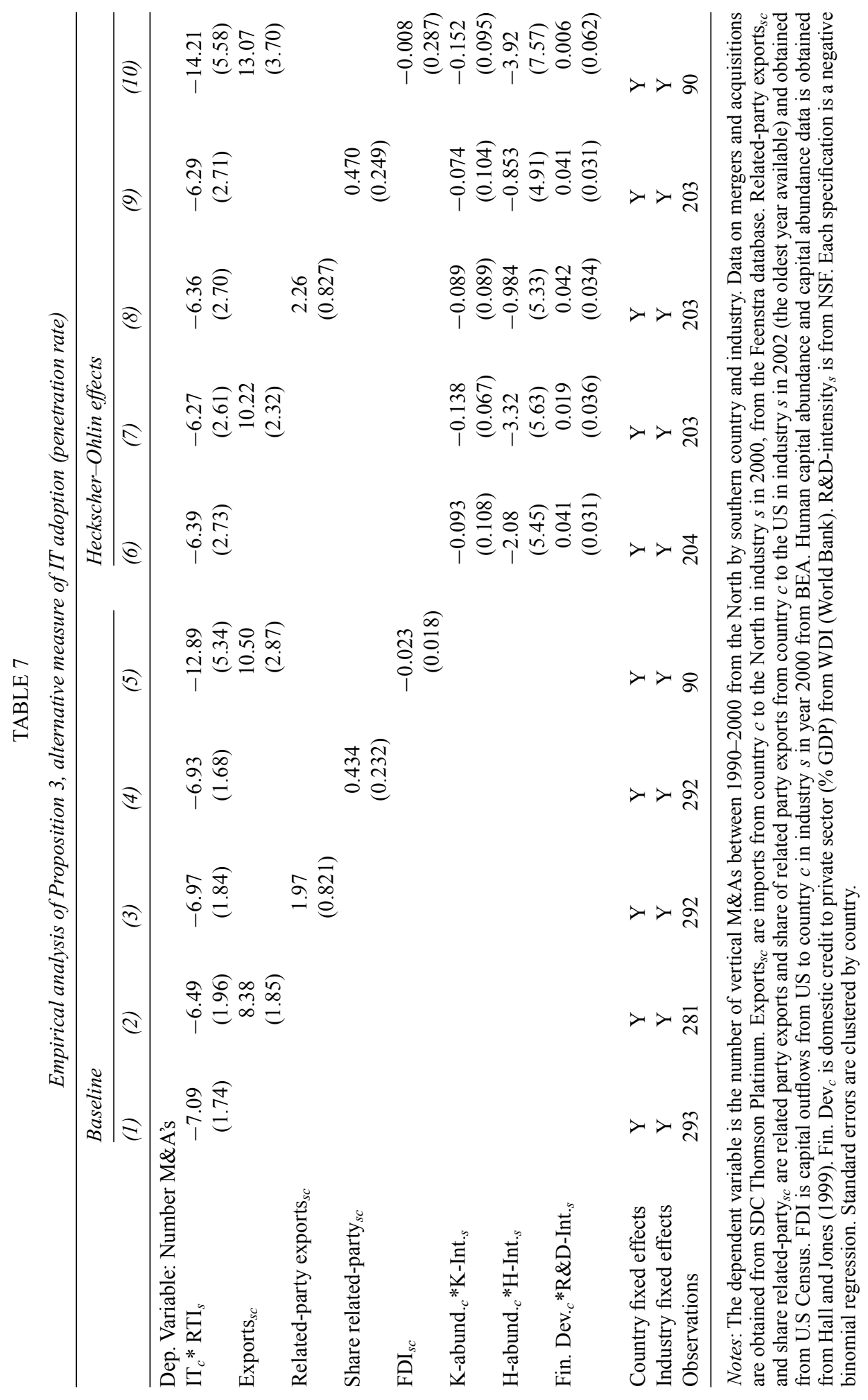


Institutions. Following the theoretical work of Antràs (2003), a growing empirical literature, which includes Bernard et al. (2010), Nunn (2007) and Nunn and Trefler (2013), has attempted to test the role of contracting institutions in intrafirm trade. Moreover, La Porta et al. (1998) and Rossi and Volpin (2004) among others emphasize the importance of property rights institutions on mergers activity and concentration of ownership. Thus, it could be argued that our measure of IT adoption is a proxy for other institutions. In order to address these concerns, column (3) adds the interaction between rule of law and RTI to the baseline specification. Analogously, column (4) includes the interaction between constraints on the executive and RTI. Following the terminology used in Acemoglu and Johnson (2005), column (3) controls for contracting institutions and column (4) controls for property rights institutions. Note that in both columns the coefficient of interest remains negative and significant. Moreover, the interactions with contracting and property rights institutions are not statistically different from zero.

Skill-intensity and technology adoption. An indirect effect of the adoption of IT technologies that we do not take into account is that it complements skills (see, for example, Autor, Levy and Murnane, 2003). Therefore, it could be that the effect of IT on the number of mergers is a function of the skill intensity of the industry, instead of the routine intensity. In other words, our measure of routine intensity may be a proxy of the skill-intensity of industry. Column (5) of Table 8 includes the interaction between skill-intensity of the industry and Internet Adoption. Note that the coefficient of interest remains negative and statistically significant. In addition, the coefficient of the interaction with skill-intensity is not significant. We also run the same regression with only this latter interaction and the coefficient remains not significant.

\section{Conclusion}

This paper provided a first attempt to empirically study how the IT revolution has changed the organization of global supply chains. We focused on international mergers and acquisitions, which are a growing and important fraction of FDI.

The premise of our analysis was that adoption of IT has reduced the costs of monitoring production. We presented a simple model that showed that this implies that the effect of IT adoption on the number of mergers is relatively larger in hard-to-monitor industries

We tested this prediction using North-South vertical mergers and acquisitions. Consistent with the prediction of the model, we showed that the effect of IT adoption on the number of M\&As is decreasing with the routine intensity of the industry. This finding is robust to alternative specifications and alternative measures of monitoring problems and IT adoption. In our baseline specification, we have found that an increase from the 25th to the 75th percentile in IT adoption implies that low routine-intensive industries (e.g. non-metallic products) would increase the number of mergers a $29 \%$ more relative to high routine-intensive industries (e.g. computer and electronics).

To conclude, our results hint to the importance of technology adoption for the organization of the firm and international trade. We plan on further pursuing the study of the interdependence between technology adoption and trade. 
TABLE 8

Empirical analysis of Proposition 3, output, technology, institutions and skills

\begin{tabular}{|c|c|c|c|c|c|}
\hline & $\begin{array}{l}\text { Output } \\
\text { (1) }\end{array}$ & $\begin{array}{l}\text { Technology } \\
\text { (2) }\end{array}$ & $\begin{array}{l}\text { Institutions } \\
\text { (3) }\end{array}$ & (4) & $\begin{array}{l}\text { Skills } \\
\text { (5) }\end{array}$ \\
\hline \multicolumn{6}{|l|}{ Dep. Variable: Number M\&As } \\
\hline $\mathrm{IT}_{c} * \mathrm{RTI}_{s}$ & $\begin{array}{c}-0.112 \\
(0.054)\end{array}$ & $\begin{array}{c}-0.115 \\
(0.053)\end{array}$ & $\begin{array}{c}-0.125 \\
(0.074)\end{array}$ & $\begin{array}{c}-0.114 \\
(0.055)\end{array}$ & $\begin{array}{r}-0.107 \\
(0.052)\end{array}$ \\
\hline $\mathrm{GDP}_{c} * \mathrm{RTI}_{s}$ & $\begin{array}{c}9.65 \\
(5.91)\end{array}$ & & & & \\
\hline $\mathrm{TFP}_{c} * \mathrm{RTI}_{s}$ & & $\begin{array}{c}0.355 \\
(0.864)\end{array}$ & & & \\
\hline Rule of $\operatorname{law}_{c} * \mathrm{RTI}_{s}$ & & & $\begin{array}{c}0.207 \\
(0.529)\end{array}$ & & \\
\hline Constraint executive $_{c} * \mathrm{RTI}_{s}$ & & & & $\begin{array}{c}0.055 \\
(0.163)\end{array}$ & \\
\hline $\mathrm{IT}_{c}{ }^{*} \mathrm{H}$-intensity ${ }_{s}$ & & & & & $\begin{array}{r}-0.230 \\
(0.588)\end{array}$ \\
\hline Exports $_{s c}$ & $\begin{array}{l}1.06 \\
(0.218)\end{array}$ & $\begin{array}{l}1.05 \\
(0.223)\end{array}$ & $\begin{array}{l}1.09 \\
(0.252)\end{array}$ & $\begin{array}{l}1.07 \\
(0.241)\end{array}$ & $\begin{array}{l}1.06 \\
(0.215)\end{array}$ \\
\hline K-abund. ${ }_{c} * \mathrm{~K}$-Int. ${ }_{s}$ & $\begin{array}{c}-0.121 \\
(0.067)\end{array}$ & $\begin{array}{c}-0.117 \\
(0.023)\end{array}$ & $\begin{array}{c}-0.128 \\
(0.065)\end{array}$ & $\begin{array}{c}-0.122 \\
(0.062)\end{array}$ & $\begin{array}{r}-0.124 \\
(0.062)\end{array}$ \\
\hline $\mathrm{H}$-abund. ${ }_{c}{ }^{*} \mathrm{H}$-Int. ${ }_{s}$ & $\begin{array}{c}-4.73 \\
(5.30)\end{array}$ & $\begin{array}{c}-4.12 \\
(5.36)\end{array}$ & $\begin{array}{c}-5.08 \\
(5.33)\end{array}$ & $\begin{array}{c}-4.63 \\
(5.41)\end{array}$ & $\begin{array}{c}-3.82 \\
(4.86)\end{array}$ \\
\hline Fin. Dev.c $*$ R\&D-Int. $s$ & $\begin{array}{c}0.036 \\
(0.037)\end{array}$ & $\begin{array}{c}0.036 \\
(0.035)\end{array}$ & $\begin{array}{c}0.034 \\
(0.035)\end{array}$ & $\begin{array}{c}0.038 \\
(0.037)\end{array}$ & $\begin{array}{c}0.032 \\
(0.036)\end{array}$ \\
\hline Country fixed effects & Y & Y & Y & Y & Y \\
\hline Industry fixed effects & $\mathrm{Y}$ & Y & Y & $\mathrm{Y}$ & Y \\
\hline Observations & 230 & 230 & 229 & 228 & 230 \\
\hline
\end{tabular}

Notes: The dependent variable is the number of vertical M\&As between 1990-2000 from the North by southern country and industry. Data on mergers and acquisitions are obtained from SDC Thomson Platinum. Exports $s c$ are imports from country $c$ to the North in industry $s$ in 2000, from the Feenstra database. Related-party exports $s_{s c}$ and share related-party ${ }_{s c}$ are related party exports and share of related party exports from country $c$ to the US. in industry $s$ in 2002 (the oldest year available) and obtained from U.S. Census. FDI is capital outflows from US to country $c$ in industry $s$ in year 2000 from BEA. Human capital abundance and capital abundance data is obtained from Hall and Jones (1999). Fin. $\operatorname{Dev}_{c}$ is domestic credit to private sector (\% GDP) from WDI (World Bank). R\&D-intensity is from NSF. Each specification is a negative binomial regression. Standard errors are clustered by country. 


\section{Appendix A. Additional tables}

Tables A1 and A2.

TABLE A1

Empirical analysis of Proposition 3, dummy variables for RTI

\begin{tabular}{|c|c|c|c|c|c|c|c|c|}
\hline & \multicolumn{4}{|c|}{ Above median } & \multicolumn{4}{|c|}{ Above average } \\
\hline & (1) & (2) & (3) & (4) & (5) & (6) & (7) & (8) \\
\hline \multicolumn{9}{|c|}{ Dep. Var. : Number M\&A’s } \\
\hline $\mathrm{IT}_{c} * \operatorname{High} \_\mathrm{RTI}_{s}$ & $\begin{array}{c}-0.033 \\
(0.016)\end{array}$ & $\begin{array}{r}-0.037 \\
(0.014)\end{array}$ & $\begin{array}{r}-0.036 \\
(0.017)\end{array}$ & $\begin{array}{c}-0.077 \\
(0.021)\end{array}$ & $\begin{array}{r}-0.028 \\
(0.014)\end{array}$ & $\begin{array}{c}-0.031 \\
(0.012)\end{array}$ & $\begin{array}{c}-0.046 \\
(0.016)\end{array}$ & $\begin{array}{r}-0.067 \\
(0.014)\end{array}$ \\
\hline Exports $_{s c}$ & & $\begin{array}{l}1.24 \\
(0.398)\end{array}$ & $\begin{array}{l}1.11 \\
(0.215)\end{array}$ & $\begin{array}{l}1.15 \\
(0.345)\end{array}$ & & $\begin{array}{l}1.23 \\
(0.364)\end{array}$ & $\begin{array}{l}1.08 \\
(0.220)\end{array}$ & $\begin{array}{l}1.21 \\
(0.339)\end{array}$ \\
\hline $\mathrm{FDI}_{s c}$ & & & & $\begin{array}{c}-0.064 \\
(0.241)\end{array}$ & & & & $\begin{array}{r}-0.088 \\
(0.244)\end{array}$ \\
\hline K-abund. ${ }_{c}^{*}$ K-Int. $s$ & & & $\begin{array}{c}-0.124 \\
(0.060)\end{array}$ & $\begin{array}{c}-0.109 \\
(0.090)\end{array}$ & & & $\begin{array}{c}-0.127 \\
(0.061)\end{array}$ & $\begin{array}{c}-0.113 \\
(0.094)\end{array}$ \\
\hline H-abund. ${ }_{c}{ }^{*} \mathrm{H}-$ Int. $s$ & & & $\begin{array}{c}-5.80 \\
(5.73)\end{array}$ & $\begin{array}{c}-6.82 \\
(8.68)\end{array}$ & & & $\begin{array}{c}-5.64 \\
(5.69)\end{array}$ & $\begin{array}{c}-6.25 \\
(8.41)\end{array}$ \\
\hline Fin. Dev. $_{.} *$ R\&D-Int. ${ }_{s}$ & & & $\begin{array}{c}0.025 \\
(0.034)\end{array}$ & $\begin{array}{c}0.036 \\
(0.058)\end{array}$ & & & $\begin{array}{c}0.032 \\
(0.035)\end{array}$ & $\begin{array}{c}0.029 \\
(0.061)\end{array}$ \\
\hline Country fixed effects & Y & $\mathrm{Y}$ & $\mathrm{Y}$ & $\mathrm{Y}$ & $\mathrm{Y}$ & $\mathrm{Y}$ & Y & $\mathrm{Y}$ \\
\hline Industry fixed effects & $\mathrm{Y}$ & $\mathrm{Y}$ & $\mathrm{Y}$ & $\mathrm{Y}$ & $\mathrm{Y}$ & $\mathrm{Y}$ & $\mathrm{Y}$ & $\mathrm{Y}$ \\
\hline Observations & 381 & 334 & 230 & 94 & 381 & 334 & 230 & 94 \\
\hline
\end{tabular}

Notes: The dependent variable is the number of vertical M\&As between 1990-2000 from the North by southern country and industry. In columns $1-4 \mathrm{High}_{-} \mathrm{RTI}_{s}$ is a dummy variable equal to one if the RTI index of the industry is above the median. Analogously, for columns 5-8 High_RTI is a dummy for when the RTI of the industry is above the average. Data on mergers and acquisitions are obtained from SDC Thomson Platinum. Exports $s c$ are imports from country c to the North in industry $s$ in 2000, from the Feenstra database. Related-party exports $s c$ and share related-party ${ }_{s c}$ are related party exports and share of related party exports from country c to the U.S. in industry $s$ in 2002 (the oldest year available) and obtained from US Census. FDI is capital outflows from US to country $c$ in industry $s$ in year 2000 from BEA. Human capital abundance and capital abundance data is obtained from Hall and Jones (1999). Fin. $\mathrm{Dev}_{c}$ is domestic credit to private sector (\% GDP) from WDI (World Bank). R\&D-intensity $y_{s}$ is from NSF. Each specification is a negative binomial regression. Standard errors are clustered by country.

\section{Appendix B. Detailed analysis of the model in section II and proofs}

We start this section by studying the problem of the headquarters of choosing whether to induce high or low effort. Consider an input in industry $s$, country $c$ and organizational mode $X$.

In case the headquarters decide to induce high effort in the production of a given task, the incentive compatibility constraint,

$$
P_{H} w_{H}-e \geqslant P_{L} w_{H}-\alpha e \pi(c, X),
$$

and the participation constraint,

$$
P_{H} w_{H} \geqslant e,
$$


TABLE A2

Empirical analysis of Proposition 3, different years of internet adoption

\begin{tabular}{|c|c|c|c|c|c|c|c|c|}
\hline & \multicolumn{4}{|c|}{ Internet 1995} & \multicolumn{4}{|c|}{ Internet 1993} \\
\hline & (1) & (2) & (3) & (4) & (5) & (6) & (7) & (8) \\
\hline \multicolumn{9}{|c|}{ Dep. Var. : Number M\&A’s } \\
\hline $\mathrm{IT}_{c} * \mathrm{RTI}_{s}$ & $\begin{array}{c}-0.829 \\
(0.210)\end{array}$ & $\begin{array}{c}-0.843 \\
(0.221)\end{array}$ & $\begin{array}{c}-0.822 \\
(0.318)\end{array}$ & $\begin{array}{c}-1.95 \\
(0.527)\end{array}$ & $\begin{array}{c}-2.24 \\
(0.924)\end{array}$ & $\begin{array}{c}-2.24 \\
(0.865)\end{array}$ & $\begin{array}{c}-1.63 \\
(0.722)\end{array}$ & $\begin{array}{c}-4.37 \\
(1.19)\end{array}$ \\
\hline Exports $_{s c}$ & & $\begin{array}{c}0.870 \\
(0.198)\end{array}$ & $\begin{array}{c}0.990 \\
(0.225)\end{array}$ & $\begin{array}{l}1.13 \\
(0.364)\end{array}$ & & $\begin{array}{c}0.880 \\
(0.207)\end{array}$ & $\begin{array}{c}0.996 \\
(0.235)\end{array}$ & $\begin{array}{c}1.11 \\
(0.392)\end{array}$ \\
\hline $\mathrm{FDI}_{s c}$ & & & & $\begin{array}{c}-0.093 \\
(0.257)\end{array}$ & & & & $\begin{array}{c}-0.081 \\
(0.248)\end{array}$ \\
\hline K-abund. ${ }_{c} *$ K-Int. $s$ & & & $\begin{array}{c}-0.097 \\
(0.057)\end{array}$ & $\begin{array}{r}-0.094 \\
(0.095)\end{array}$ & & & $\begin{array}{c}-0.096 \\
(0.060)\end{array}$ & $\begin{array}{r}-0.099 \\
(0.095)\end{array}$ \\
\hline $\mathrm{H}$-abund. ${ }_{c} * \mathrm{H}$-Int. ${ }_{s}$ & & & $\begin{array}{c}-3.72 \\
(5.60)\end{array}$ & $\begin{array}{c}-3.68 \\
(7.84)\end{array}$ & & & $\begin{array}{c}-4.54 \\
(6.19)\end{array}$ & $\begin{array}{c}-4.90 \\
(8.64)\end{array}$ \\
\hline Fin. Dev. ${ }_{c} *$ R\&D-Int. ${ }_{s}$ & & & $\begin{array}{c}0.019 \\
(0.038)\end{array}$ & $\begin{array}{c}0.009 \\
(0.072)\end{array}$ & & & $\begin{array}{c}0.022 \\
(0.039)\end{array}$ & $\begin{array}{c}0.011 \\
(0.073)\end{array}$ \\
\hline Country fixed effects & $\mathrm{Y}$ & $\mathrm{Y}$ & $\mathrm{Y}$ & Y & Y & Y & $\mathrm{Y}$ & $\mathrm{Y}$ \\
\hline Industry fixed effects & $\mathrm{Y}$ & $\mathrm{Y}$ & $\mathrm{Y}$ & $\mathrm{Y}$ & $\mathrm{Y}$ & $\mathrm{Y}$ & $\mathrm{Y}$ & $\mathrm{Y}$ \\
\hline Observations & 335 & 305 & 222 & 94 & 280 & 259 & 183 & 83 \\
\hline
\end{tabular}

Notes: The dependent variable is the number of vertical M\&As between 1990-2000 from the North by southern country and industry. In columns $1-4, \mathrm{IT}_{c}$ is Internet Adoption in 1995. Analogously, for columns $\mathrm{IT}_{c}$ is Internet Adoption in 1993. Data on mergers and acquisitions are obtained from SDC Thomson Platinum. Exports $s c$ are imports from country $\mathrm{c}$ to the North in industry s in 2000 , from the Feenstra database. Related-party exports $s c$ and share relatedparty $s c$ are related party exports and share of related party exports from country c to the U.S. in industry s in 2002 (the oldest year available) and obtained from US Census. FDI is capital outflows from US to country $\mathrm{c}$ in industry s in year 2000 from BEA. Human capital abundance and capital abundance data is obtained from Hall and Jones (1999). Fin. $\operatorname{Dev}_{c}$ is domestic credit to private sector (\% GDP) from WDI (World Bank). R\&D-intensity is from NSF. Each specification is a negative binomial regression. Standard errors are clustered by country.

need to be satisfied (following the main text we are normalizing the outside option of an agent to zero). Thus, in this case the wage offered has to satisfy simultaneously equations (B.1) and (B.2). That is,

$$
w_{H}=\max \left\{e \frac{1-\alpha \pi(c, X)}{P_{H}-P_{L}}, \frac{e}{P_{H}}\right\} .
$$

Note that, if the incentive compatibility constraint is binding when inducing high effort, it has to be the case that

$$
\frac{1-\alpha \pi}{P_{H}-P_{L}}>\frac{1}{P_{H}} .
$$

This is ensured if the monitoring technology $\pi$ is sufficiently imperfect, or if the penalty imposed $\alpha$ in case of shirking is not arbitrarily large. In what follows we assume that $\alpha \pi<P_{L} / P_{H}$, which ensures that the incentive compatibility constraint is always binding when inducing high effort.

Assumption 2. The monitoring technology, $\pi$, is sufficiently imperfect and the penalty imposed, $\alpha$, is not arbitrarily large so that 


$$
\alpha \pi<\frac{P_{L}}{P_{H}} .
$$

If the headquarters decide to induce low effort, they just pay agents their outside option to satisfy the participation constraint, which we have normalized to zero.

We can analyze now whether it is more profitable to induce high or low effort for the headquarters. This boils down to comparing the expected output of a task for a worker that exerts high or low effort in a given task. Headquarters choose to induce high effort if and only if the expected output minus the payment to a worker is higher. That is, if

$$
P_{H} a(j) 1-e(c) \frac{1-\alpha \pi(c, X)}{P_{H}-P_{L}} \geqslant P_{L} a(j) 1,
$$

where the 1 stands for the unit of labor provided by a worker. Let $\underline{a}$ denote the lowest productivity in the support of possible productivities of a firm. Then, a sufficient condition for headquarters to always want to implement high effort is

$$
\left(P_{H}-P_{L}\right)^{2} \underline{a} \geqslant \max _{c \in C} e(c) \text {. }
$$

We assume that the difference in probabilities is large enough so that condition (B.6) holds. Thus, inducing high effort is always optimal.

Assumption 3. The difference in probabilities between high and low effort satisfies

$$
P_{H}-P_{L} \geqslant \sqrt{\frac{\max _{c \in C} e(c)}{\underline{a}}} .
$$

Thus, the payment offered for a discretional task $t$ under organizational choice $X$ in country $c$ is

$$
w(t, c, X)=\frac{1-\alpha \pi(c, X)}{P_{H}-P_{L}} e(c) .
$$

The payment to a standardized task is the outside option because of the perfect observability assumption. The total payment to a worker in a industry in which there are $s$ standardized tasks is the sum of the payments for all discretional tasks,

$$
(\mathcal{T}-s) \frac{1-\alpha \pi(c, X)}{P_{H}-P_{L}} e(c) .
$$

Proof of Proposition 1. Consider two industries $s$ and $s^{\prime}$ such that $s<s^{\prime}$ for which we observe some mergers in country $c$. The ceteris paribus assumption implies that the cost of the marginal input being offshored is the same $\kappa(s)=\kappa\left(s^{\prime}\right)$ and that the measure of offshored inputs is the same, $N_{s}=N_{s^{\prime}}$. We show the result by contradiction. Suppose that the number of mergers in industry $s, M_{s}$, is greater than in industry $s^{\prime}, M_{s^{\prime}}$. That is $M_{s}>M_{s^{\prime}}$. Note that the marginal merger in industry $s$ is in country $c$ (amongst possibly other countries). This means that

$$
\kappa(s)=\frac{R(s, c, M) w_{c}}{a(s, c, M)} .
$$


Note that we have that $R\left(s^{\prime}, c, M\right)<R(s, c, M)$ and that, by assumption, $\kappa(s)=\kappa\left(s^{\prime}\right)$. This implies that $a\left(s^{\prime}, c, M\right)<a(s, c, M)$, which implies that $1-F\left(a\left(s^{\prime}, c, M\right)\right)>1-$ $F(a(s, c, M))$, i.e. $M_{s}<M_{s^{\prime}}$. A contradiction.

Proof of Proposition 2. Let us denote by $i=0$ the level of Internet adoption before the IT revolution. Consider a level of IT adoption $i>0$ in country $c$. Consider two industries $s, s^{\prime}$ with $s^{\prime}>s$. Thus, $R(s, c, X ; i)>R\left(s^{\prime}, c, X ; i\right)$. Suppose that at $i=0$ neither industry experienced mergers. We show by contradiction that it is not possible that there are mergers at $i$ in industry $s$ but not in $s^{\prime}$. The ceteris paribus assumption implies that the maximal cost of production and that the total number of inputs to be offshored are equal, $\kappa(s)=\kappa\left(s^{\prime}\right)$ and $N_{s}=N_{s^{\prime}}$. Suppose that there are mergers in industry $s$ and not in $s^{\prime}$. Let $\tilde{a}(s, c, M)$ denote the least productive acquired firm in industry $s$. This implies that the marginal cost of production is

$$
\frac{R(s, c, M ; i)}{\tilde{a}(s, c, M)}=\kappa(s) .
$$

Note that in this model, if mergers are preferred in one sector in one country, then mergers are preferred to arm's length contracting in all sectors in this country.

This implies that

$$
\frac{R\left(s^{\prime}, c, M ; i\right)}{\tilde{a}(s, c, M)}<\kappa\left(s^{\prime}\right),
$$

a contradiction, because it would be possible to produce at lower cost than what is being done in equilibrium.

Proof of Proposition 3. Consider first the case in which no $O$-organization is ever operating in country $c$. Suppose further that only country $c$ receives mergers. In this case, the number of mergers remains constant, as the total number of inputs is fixed to $N_{s}$. Suppose now that there are only mergers in $c$ but that another country $c^{\prime}$ is also supplying inputs. Suppose we want to compare two sectors $s$ and $s^{\prime}$. The ceteris paribus assumption implies that the maximal cost of production and that the total number of inputs to be offshored are equal, $\kappa(s)=\kappa\left(s^{\prime}\right)$ and $N_{s}=N_{s^{\prime}}$ In fact, the maximal cost of production $\bar{\kappa}(s)$ remains constant because it is pinned downed by $c^{\prime}$. The ceteris paribus assumption ensures that $\bar{\kappa}(s)$ is constant around $s$. We have that the number of firms operating is $1-F(a(s, c, M ; i))=1-F\left(\bar{\kappa}(s) w_{c} R(s, c, M ; i)\right)$. Taking the 'derivative' of this expression with respect to $s$ and $i$ yields ${ }^{33}$

$$
-f^{\prime}\left(\bar{\kappa}(s) w_{c} R(s, c, M ; i)\right) \bar{\kappa}(s)^{2} R_{i} R_{s}-f\left(\bar{\kappa}(s) w_{c} R(s, c, M ; i)\right) R_{s i}<0,
$$

where $f^{\prime}(\cdot)$ denotes the first derivative of the density function and $R_{x}$ denotes the partial derivative of $R$ with respect to $x$. As $f^{\prime}<0, R_{s}<0, R_{i}<0$ and $R_{s i}>0$ (see equation 2), the result follows.

Consider now the case in which there are both $O$ - and $M$-organizations for some $s$ and $s^{\prime}$. In this case, we have that the ratio $R(s, c, M ; i) / R(s, c, O ; i)$ is independent of $s$. Hence the 'cross partial' is zero.

\footnotetext{
${ }^{33}$ To be more precise, the derivative expression with respect to $s$ has to be understood as a first difference, as $s \in \mathbf{N}$.
} 
Finally, note that the intermediate case of starting with no $O$-organization before the Internet revolution and incorporating $O$-activity during the Internet revolution is a combination of the two previous cases. Hence, by dividing the problem in two sub-periods, one where there is no $O$-activity and another where there is at least one $O$-organization, the result follows.

Final Manuscript Received: November 2016

\section{References}

Acemoglu, D. and Johnson, S. (2005). 'Unbundling institutions', Journal of Political Economy, Vol. 113, pp. 949-995.

Alfaro, L. and Charlton, A. (2009). 'Intra-industry foreign direct investment', American Economic Review, Vol. 99, pp. 2096-2119.

Allison, P. D. and Waterman, R. (2002). 'Fixed effects negative binomial regression models', in Stolzenberg Ross M. (ed.), Sociological Methodology 2002. Oxford: Basil Blackwell.

Antràs, P. (2003). 'Firms, contracts, and trade structure', Quarterly Journal of Economics, Vol. 118, pp. 13751418.

Antràs, P. (2014). 'Grossman-Hart (1986) Goes global: incomplete contracts, property rights, and the international organization of production', Journal of Law, Economics, and Organization, Vol. 30, pp. 118-175.

Antràs, P. and Caballero, R. (2009). 'Trade and capital flows: a financial frictions perspective', Journal of Political Economy, Vol. 117, pp. 701-744.

Antràs, P. and Chor, D. (2013). 'Organizing the global value chain', Econometrica, Vol. 81, pp. 2127-2204.

Antràs, P., Desai, M. and Foley, F. C. (2009). 'Multinational firms, FDI flows and imperfect capital markets', Quarterly Journal of Economics, Vol. 124, pp. 1171-1219.

Antràs, P., Garicano, L. and Rossi-Hansberg, E. (2006a). 'Offshoring in a knowledge economy', The Quarterly Journal of Economics, Vol. 121, pp. 31-77, 02.

Antràs, P., Garicano, L. and Rossi-Hansberg, E. (2006b). Organizing Offshoring: Middle Managers and Communication Costs, NBER Working Papers No. 12196.

Antràs, P. and Helpman, E. (2004). 'Global sourcing', Journal of Political Economy, Vol. 112, pp. 552-580.

Antràs, P. and Helpman, E. (2008). 'Contractual frictions and global sourcing', in Helpman E., Marin D., and Verdier T. (eds), The Organization of Firms in a Global Economy, Cambridge, MA: Harvard University Press, pp. 9-54.

Arnold, M. J. and Javorcik, B. (2009). 'Gifted kids or pushy parents? Foreign direct investment and plant productivity in Indonesia', Journal of International Economics, Vol. 79, pp. 42-53.

Atalay, E., Hortacsu, A. and Syverson, C. (2014). 'Vertical integration and input flows', American Economic Review, Vol. 104, pp. 1120-1148.

Autor, D. and Dorn, D. (2008). 'The growth of low-skill service jobs and the polarization of the United States', American Economic Review, Vol. 103, pp. 1553-1597.

Autor, D. and Dorn, D. (2009). 'This job is 'getting old': measuring changes in job opportunities using occupational age structure', American Economic Review Papers and Proceedings, Vol. 99, pp. 45-51.

Autor, D., Levy, F. and Murnane, R. J. (2003). 'The skill content of recent technological change: an empirical exploration', The Quarterly Journal of Economics, Vol. 118, pp. 1279-1333.

Baker, G. and Hubbard, T. N. (2003). 'Make versus buy in trucking: asset ownership, job design, and information', The American Economic Review, Vol. 93, pp. 551-572.

Baldwin, R. (2006). 'Globalisation: the great unbundling(s)', Economic Council of Finland.

Baldwin, R. (2012). Global Supply Chains: Why They Emerged, Why They Matter, and Where They are Going, CTEI Papers, CTEI-2012-3.

Basco, S. (2012). 'Financial development and the product cycle', Journal of Economic Behavior and Organization, Vol. 94, pp. 295-313. 
Basco, S. and Mestieri, M. (2013). 'Heterogeneous trade costs and wage inequality: a model of two globalizations', Journal of International Economics, Vol. 89, pp. 393-406.

Basco, S. and Mestieri, M. (2016). Mergers Along the Global Supply Chain: Information Technologies and Routineness, Working Paper, available at sites.google.com/site/sergibasco.

Bernard, A., Jensen, J., Redding, S. and Schott, P. (2010). 'Intra-firm trade and product contractibility', American Economic Review, Vol. 100, pp. 444-448.

Blinder, A. S. (2006). 'Offshoring: the next industrial revolution?', Foreign Affairs, Vol. 85, pp. 113-128.

Bloom, N., Brynjolfsson, E., Foster, L., Jarmin, R., Saporta-Eksten, I. and Van Reenen, J. (2013). Management in America, CES Discussion Paper No. 13-01, January 2013.

Bloom, N., Garicano, L., Sadun, R. and Van Reenen, J. (2014). 'The distinct effects of information technology and communication technology on firm organization', Management Science, Vol. 60, pp. 2859-2885.

Breinlich, H. (2008). 'Trade liberalization and industrial restructuring through mergers and acquisitions', Journal of International Economics, Vol. 76, pp. 254-266.

Carluccio, J. and Fally, T. (2012). 'Global sourcing under imperfect capital markets', The Review of Economics and Statistics, Vol. 94, pp. 740-763.

Comin, D. and Mestieri, M. (2010). An Intensive Exploration of Technology Diffusion, NBER Working Paper No. 16379.

Crinò, R. (2010). 'Service offshoring and white-collar employment', Review of Economic Studies, Vol. 77, pp. 595-632.

Eaton, J., Kortum S. and Kramarz, F. (2011). 'An anatomy of international trade: evidence from french firms', Econometrica, Vol. 79, pp. 1453-1498.

Ebenstein, A., Harrison, A., McMillan, M. and Phillips, S. (2014). 'Estimating the impact of trade and offshoring on American workers using the current population surveys', Review of Economics and Statistics, Vol. 96, pp. 581-595.

Fort, T. (2016). Technology and Production Fragmentation: Domestic Versus Foreign Sourcing, NBER Working Paper No. 22550

Freund, C. L. and Weinhold, D. (2004). 'The effect of the Internet on international trade', Journal of International Economics, Vol. 62, pp. 171-189.

Grossman, S. J., and Hart, O. D. (1986). 'The costs and benefits of ownership: a theory of vertical and lateral integration', Journal of Political Economy, Vol. 94, pp. 691-719.

Grossman, G. M. and Rossi-Hansberg, E. (2006). 'The rise of offshoring: it's not wine for cloth anymore', Proceedings-Economic Policy Simposium-Jackson Hole, Federal Reserve Bank of Kansas City, pp. 59-102.

Guadalupe, M., Kuzmina, O. and Thomas, C. (2012). 'Innovation and foreign ownership', American Economic Review, Vol. 102, pp. 3594-3627.

Hall, R. E. and Jones, C. I. (1999). 'Why do some countries produce so much more output per worker than others?', Quarterly Journal of Economics, Vol. 114, pp. 83-116.

Head, K. and Ries, J. (2008). 'FDI as an outcome of the market for corporate control: theory and evidence', Journal of International Economics, Vol. 74, pp. 2-20.

Javorcik, B. (2004). 'The composition of foreign direct investment and protection of intellectual property rights: evidence from transition economies', European Economic Review, Vol. ??, pp. 39-62.

Javorcik, B. and Poelhekke, S. (2016). 'Former foreign affiliates: cast out and outperformed?' Journal of the European Economic Assocation, forthcoming.

Kletzer, K. and Bardhan, P. K. (1987). 'Credit markets and patterns of international trade', Journal of Development Economics, Vol. 27, pp. 57-70.

La Porta, R., Lopez-de-Silanes, F., Shleifer, A. and Vishny, R. (1998). 'Law and finance', Journal of Political Economy, Vol. 106, pp. 1113-1155.

Manova, K. (2013). 'Credit constraints, heterogeneous firms, and international trade', Review of Economic Studies, Vol. 80, pp. 711-744.

Neary, P. (2007). 'Cross-border mergers as instruments of comparative advantage', Review of Economic Studies, Vol. 74, pp. 1229-1257.

Nocke, V. and Yeaple, S. (2007). 'Cross-border mergers and acquisitions vs. greenfield foreign direct investment: the role of firm heterogeneity', Journal of International Economics, Vol. 72, pp. 336-365. 
Nocke, V. and Yeaple, S. (2008). 'An assignment theory of foreign direct investment', Review of Economic Studies, Vol. 75, pp. 529-557.

Nunn, N. (2007). 'Relationship-specificity, incomplete contracts, and the pattern of trade', Quarterly Journal of Economics, Vol. 122, pp. 569-600.

Nunn, N. and Trefler, D. (2013). 'Incomplete contracts and the boundaries of the multinational firm', Journal of Economic Behavior and Organization, Vol. 94, pp. 330-344.

Oldenski, L. (2011). The Task Composition of Offshoring by U.S. Multinationals, mimeo, Georgetown University.

Ramondo, N., Rappoport, V. and Ruhl, K. (2012). 'Horizontal Versus Vertical FDI: Revisiting Evidence About U.S. Multinationals', mimeo.

Romalis, J. (2004). 'Factor proportions and the structure of commodity trade', American Economic Review, Vol. 94, pp. 67-97.

Rossi, S. and Volpin, P. F. (2004). 'Cross-country determinants of mergers and acquisitions', Journal of Financial Economics, Vol. 74, pp. 277-304.

UNCTAD (2000).World Investment Report 2000, United Nations, New York.

UNCTAD (2013).World Investment Report 2013, United Nations, New York.

Williamson, O. (1975). Markets and Hierarchies: Analysis and Antitrust Implications, Chapters 4 and 5, Free Press, New York, NY. 